\section{Summary}

One hundred women with incoordinate uterine action had labour managed under continuous epidural analgesia, the average duration of the block being 10 hours. Most of the patients were primigravidae, many were of small stature, and many had large babies, commonly with the occiput in the posterior position. Graphic analysis of labour showed an increased rate of cervical dilatation after epidural block in over $70 \%$. The caesarean section rate remained high $(55 \%)$ in cases complicated by mechanical dystocia, but where this was not present the caesarean section rate was much lower (14\%), while in those patients who had no cephalopelvic disproportion and who showed an increased rate of dilatation after epidural block the caesarean section rate was only $3.8 \%$. With this management, caesarean section is rarely required purely for incoordinate uterine action or maternal distress.

The perinatal mortality in the series was $2 \%$, and there were no serious maternal complications.

Dr. John MacVicar provided the initial stimulus for this work, and our thanks are due to him and to Professor Ian Donald for continued encouragement and help. The work could not have been done without the untiring efforts of the labour room staff, whose cheerful co-operation was much appreciated.

\section{REFERENCES}

Adamson, D. H., and Spoerel, W. E. (1966). Acta anaesth. scand., Suppl. No. 23 , p. 379.

Arthur, H. R., and Jahnson, G. T. (1952). \}. Obstet. Gynaec. Brit. Emp., 59,372 .

Ball, H C. J., and Chambers, J. S. W. (1956). Brit. med. F., 1, 1275.

Blecher, T. E., Edgar, W. M., Melville, H. A. H., and Peel, K. R. (1966). Ibid., 1, 137 .

Bromage, P. R. (1962), Brit. F. Anaesth., 34, 161.

Bromage, P. R. (1962), Brit. F. Anaesth., 34, 161. Ibid., 36, 342.

Bryce-Smith, R., and Williams, E. O. (1955). Lancet, 1, 1241.

Bush, R. C. (1959). Anesthesiology, 20, 31.

Claye, A. (1961). f. Obstet. Gynaec. Brit. Cwlth, 68, 577.
Cole, P. V. (1964). Anaesthesia, 19, 562.

Cox, J. M. R., and Spoerel, W. E. (1964). Canad. Anaesth Soc. F., 11, 72 Edmonds-Seal, J. (1964). Anaesthesia, 19, 222.

Friedman, E. A. (1954). Amer. F. Obstet. Gynec., 68, 1568.

- (1955). Obstet. and Gynec., 6, 567.

- (1956). Ibid., 8, 691.

(1965). In Obstetrics, 13th ed., by J. P. Greenhill, p. 832. Philadelphia and London.

- and Sachtleben, M. R. (1961a). Obstet. and Gynec., 17, 135.

- - (1961b). Ibid., 17, 566 .

- (1962a). Ibid., 19, 576.

- (1962b). Ibid., 20, 761.

- (1963a). Ibid., 21, 13.

- (1963b). Ibid., 22, 478 .

Galley, A. H. (1949). Anaesthesia, 4, 154.

Galley, A. H. (1949). Anaesthesia, 4, 154.

Glasgow Royal Maternity Hospital (1962). Clinical Report.

Greiss, F. C., and Wilkes, D. V. (1964). Obstet. and Gynec., 23, 925.

Hellmann, K. (1965). Canad. Anaesth. Soc. F., 12, 398.

Hingson, R. A., Cull, W. A., and Benzinger, M (1961) Anaesth. Analg. Curr. Res., 40, 119.

and Edwards, W. B. (1943). f. Amer. med. Ass., 121, 225.

effcoate, T. N. A. (1961). Lancet, 2, 61.

- (1965). Aust. N.Z.f. Obstet. Gynaec., 5, 222.

Baker, K., and Martin, R. H. (1952). 'Surg. Gynec. Obstet., 95,

Johnson, G. T. (1952). 7. Obstet. Gynaec. Brit. Emp., 59, 644.

- (1954). Brit. med. F., 1, 627.

(1957). Ibid., 2, 386.

Lee, J. A. (1962). Anaeshesia, 17, 248.

Mark, R. F. (1961). 7. Obstet. Gynaec. Brit. Cwlth, 68, 584.

Moir, D. D., and Hesson, W R (1965) Anaesthesia, 20, 373

- and Wallace, G. (1967). In press.

- and Willocks, J. (1966). Acta anaesth. scand., Suppl. No. 23, p. 144.

Moore, D. C. (1966). In discussion on obstetric anaesthesia at the Second European Congress of Anaesthesiology.

National Maternity Hospital, Dublin (1964). Clinical Report.

Norris, S., Harris, L. J., and Eisen, S. M. (1960). Obstet. and Gynec. 16, 15 .

Rodesch, F., Ehman-Ellinger, C., Wilkin, P., and Hubinont, P. O. (1965). f. Obset. Gynaec. Brit. Cwilth, 72, 930 .

Royal Maternity Hospital, Belfast (1963). Clinical Report.

Scott, D. B. (1955). Lancet, 2, 43.

Smellie, W. (1752). Treatise on the Theory and Practice of Midwifery.

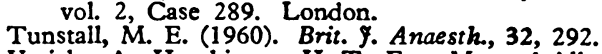

Vasicka, A., Hutchinson, H. T., Eng, M., and Allen, C. R. (1964). Amer 9. Obstet. Gynec., 90, 800 .

Williams, J. D., and Felton, D. J. C. (1966). F. Obstet Gynaec. Brit. Cwlth., 73, 654.

\title{
Value of Rectal Biopsy in Paediatric Neurology: Report of 165 Biopsies
}

\author{
E. M. BRETT,* D.M., M.R.C.P. ; C. L. BERRY, † M.B., B.S.
}

Biopsy of neural tissue, with subsequent histopathological, chemical, and histochemical examination, plays an important part in the investigation of suspected degenerative disease of the central nervous system in infancy and childhood. For a number of reasons brain biopsy is not always acceptable to parent or clinician.

The possibility of using rectal biopsy as a diagnostic test for progressive degenerative brain disease seems to have been first suggested by the necropsy observation of Globus (1942), who noted similar degenerative changes in neurones of the central nervous system and of the myenteric plexus in a case of amaurotic idiocy. Landing and Freiman (1957) encountered similar necropsy findings in various forms of amaurotic idiocy, Niemann-Pick's disease and Hurler's syndrome; and Nakai and Landing (1960) suggested that rectal biopsy might be used in the diagnosis of neurolipidosis. Kobayashi (1960) proposed the use of biopsy of the rectal wall or appendicectomy for the histochemical demonstration of "the dystrophic deposit in

\footnotetext{
- Senior Registrar in Nearology, the National Hospital for Nervous Diseases, Queen Square, and Department of Neurology, Hospital for Diseases, Queen Square, and Department of Neurology,

t Lecturer in Morbid Anatomy, the Institute of Child Health, London W.C.1.
}

ganglion cells of the myenteric plexus" in gargoylism. A series of 75 rectal biopsies was reported by Martin, Landing, and Nakai (1963), but many of these were from patients with suspected Hirschsprung's disease or were incidental to operations for imperforate anus, and only 11 seem to have been intended primarily to further the neurological diagnosis. No specific neurological diagnoses were reached as a result of these biopsies, but the authors believed that rectal biopsy might be as reliable as brain biopsy in the neural lipidoses, and that it should probably be considered in the diagnostic investigation of any otherwise unexplained degenerative neurological disorder of childhood.

Bodian and Lake (1963) reviewed 21 necropstes in which complete agreement was found between neuronal changes in the central nervous system and in the gastrointestinal tract, and there was also evidence of metachromasia in the latter if present in the brain. They further reported a series of 49 rectal biopsies based on this study ; 26 of these were normal and 23 showed abnormalities. The latter included 12 cases with changes regarded as non-specific, and 11 with diagnostic features (seven cases of neurolipidosis and four of metachromatic leucodystrophy. The authors suggested that this 
investigation "embraces the spectrum of neurolipidosis, metachromatic leucoencephalopathy, and possibly sudanophilic leucodystrophy." They believed that these biopsies were far safer than brain biopsy and might well be obtained at an early stage of the evolution of the various diseases.

In subsequent years many more rectal biopsies have been performed at the Hospital for Sick Children, Great Ormond Street, and in this paper we review the results of 165 biopsies from 164 patients over the five-year period 1962-6. These include 47 of Bodian and Lake's series (but not the two performed at other hospitals) and 118 more recent biopsies.

\section{Methods}

Full-thickness rectal biopsies were performed under general anaesthesia. For the initial six months of the period considered, half the tissue obtained was fixed in buffered formalin and then sectioned on a freezing microtome. The remaining tissue from these biopsies and all later material was frozen on solid carbon dioxide. Sections measuring $5-7 \mu$ were then cut in a cryostat.

Specimens were stained by haematoxylin and eosin, periodicacid Schiff (P.A.S.), Sudan black, scharlach red, luxol-fast blue, toluidine blue, cresyl-fast violet, Feyrter's thionine, and, where appropriate, a colloidal iron method for interstitial mucopolysaccharide (for details of methods see Bodian and Lake, 1963).

The sections were reviewed by one of us (C. L. B.) without knowledge of the clinical status of the patients. In a few cases review of the earlier sections has resulted in the original interpretation being altered in the light of subsequent histological experience.

\section{Biopsies with Positive Diagnostic Abnormalities}

Of the 165 biopsies 33 (20\%) showed positive diagnostic features. The proportion of positive biopsies was $20 \%$ for children in the total group, $31 \%$ for those under the care of the neurological unit, and $13.5 \%$ for those in other wards.

Clinical Diagnosis in 33 Cases with Positive Biopsies.Thirty of these, or approximately $90 \%$, were from patients with neurolipidosis or metachromatic leucodystrophy, as in the initial series of Bodian and Lake. There were 19 cases of neurolipidosis and 11 of metachromatic leucodystrophy. Hurler's syndrome provided two cases, and there was one case of Niemann-Pick's disease.

Duration of Symptoms at Time of Biopsy.-In neurolipidosis it was less than one year in eight, one year in three, two years in three, three years in two, and four years or more in two. One case was of doubtful duration. Five of the eight cases diagnosed by biopsy after less than one year of symptoms were examples of Tay-Sachs disease. In the cases of metachromatic leucodystrophy the duration of symptoms was less than one year in three, two years in two, three years in two, and four years in three, one case being of uncertain duration.

\section{Clinical Features of Cases with Positive Biopsies}

A history of dementia or regression in psychomotor skills was the most prominent feature in the two major diseases, being present in 17 of the 19 cases of neurolipidosis and in 9 of the 11 cases of metachromatic leucodystrophy. Convulsions occurred in seven of the neurolipidosis cases. A family history of an affected sibling occurred in five cases of neurolipidosis with biopsies in two pairs of siblings, and in seven cases of metachromatic leucodystrophy, including three pairs of siblings. The family history was suggestive in one further case of metachromatic leucodystrophy - a child whose sibling had died with a progressive neurological condition but without necropsy.

Macular changes were recorded in seven patients with neurolipidosis, five of whom, regarded clinically as examples of
Tay-Sachs disease, showed pathognomonic cherry-red spots, bilateral in four cases. Optic atrophy was noted in a further two patients in this group.

Specific features deserving comment in the 11 cases of metachromatic leucodystrophy include a history of ataxia in four patients. In three of these unsteadiness seems to have been the presenting symptom, preceding dementia, the ages of onset being 6,11 , and 16 months. This conforms to the recognized pattern of infantile form of metachromatic leucodystrophy (Allen, 1964).

The occurrence of convulsions in two siblings with metachromatic leucodystrophy was rather unexpected, since these are regarded as infrequent in this disease (Lyon, Arthuis, and Thieffry, 1961 ; Allen, 1964).

Ancillary investigations pointing to the diagnosis (later proved by biopsy) were most helpful in the 11 patients with metachromatic leucodystrophy. In these the urine showed intracellular metachromatic material in all the eight cases in which it was examined by the method of Lake (1965). The conduction velocity in peripheral nerves was measured in nine cases and found to be substantially decreased in eight ; seven of these were previously reported by Fullerton (1964). Cholecystography by the oral route was performed in one patient with positive urine and abnormal conduction velocity, and the gall bladder showed no concentration of dye.

Laboratory tests proved less helpful in the patients with neurolipidosis. In one recent case the serum fructose-1phosphate aldolase was found to be deficient ( 0.3 unit per ml. of serum) (Profesor J. N. Cumings); the level of this enzyme has recently been reported to be abnormally low in Tay-Sachs disease (Volk, Aronson, and Saifer, 1964; Schneck, Maisel, and Volk, 1964), and its measurement has been suggested as a useful screening test for this condition.

Pneumoencephalography gave evidence of cerebral atrophy in five of the six cases of neurolipidosis in which it was performed. In the two cases of metachromatic leucodystrophy so investigated the results were normal. This, with the finding of cerebral atrophy in 23 of the 35 air encephalograms in patients whose rectal biopsies were normal or showed nonspecific changes, suggests that air encephalography is not a particularly useful investigation in the selection of patients for rectal biopsy. The situation is different when a cerebral biopsy is considered; this should be preceded by an air encephalogram in order to exclude a congenital cerebral malformation of a kind which might alter the prognosis and management of the patient.

\section{Biopsies without Diagnostic Abnormalities}

On review, 132 biopsies taken from 131 patients were thought to show no abnormality.

Analysis of the major clinical features of these cases shows that, in contrast to the cases with positive biopsies, amentia or very early retardation with or without convulsions was the most frequent feature, occurring in 67 cases. Dementia occurred in only 29 cases, roughly one-fifth of the total. There were 15 patients with infantile spasms and 11 with autistic or psychotic features. In five cases without dementia or epilepsy the indication for biopsy was a family history suggesting a progressive cerebral degeneration or the finding of macular changes raising the possibility of such a condition. There were three patients with epilepsy alone and one in whom acute transient deterioration accompanied the sudden onset of epilepsy.

\section{Biopsies with Non-specific Abnormalities}

Fourteen of the 132 non-diagnostic biopsies, taken from 13 patients, were on review thought to show non-specific degenera- 
tive changes. These are listed below. ${ }^{1}$ One patient, a boy with mental and neurological deterioration in association with intractable epilepsy, had two biopsies performed at an interval of 14 months, and similar non-specific abnormalities were seen in both. Nine of the 12 biopsies reported by Bodian and Lake as showing non-specific degenerative changes were thought on review to be within normal iimits.

Analysis of the clinical features of the 13 patients with nonspecifically abnormal biopsies shows that there were six with dementia and six with amentia. This contrasts with the predominance of dementia in the cases with positive (diagnostic) biopsies and with that of amentia in those with " negative" biopsies. Epilepsy was prominent in the histories of these patients, occurring in $61 \%$, whereas it occurred in $27 \%$ of those with positive and $37 \%$ (excluding infantile spasms) of those with negative biopsies. The epilepsy was severe and intractable in many patients in this group, and the non-specific changes seen in their biopsies may perhaps reflect anoxia or other secondary effects of uncontrolled fits over long periods rather than any underlying primary degenerative disease.

\section{Confirmation by Cerebral Biopsy or Necropsy}

There were 13 cases in which, usually during the same hospital admission, both rectal and cerebral biopsies were carried out, the rectal usually preceding the cerebral biopsy. In six cases both biopsies were normal. Six patients, four with neurolipidosis and two with metachromatic leucodystrophy, showed diagnostic abnormalities in both biopsies. In one patient with subacute sclerosing leucoencephalitis cerebral biopsy showed diagnostic features of this disease, whereas rectal biopsy was normal.

Adequate necropsy studies are known so far to have been made in only seven patients with diagnostic rectal biopsies. These confirmed the diagnosis, in three cases of neurolipidosis and in four of metachromatic leucodystrophy, made on rectal biopsy. No post-mortem studies are so far known to have been made on patients whose rectal biopsies were normal or non-specifically abnormal.

\section{Morbidity}

The only complication encountered with any frequency in this series was rectal haemorrhage, which occurred in 13 cases $(8 \%)$. Haematoma formation was seen in three patients and required drainage. Five patients needed blood transfusion postoperatively.

\section{Discussion}

In this series most of the positive rectal biopsies were from patients with neurolipidosis or metachromatic leucodystrophy. The successful selection of cases for such biopsies would therefore seem largely to depend on a high clinical likelihood of one of these specific diagnoses.

There were clear pointers, clinically or on investigation, to the diagnosis in 11 of the 19 neurolipidosis patients; these included macular changes, a family history of an affected sibling, and deficiency of serum fructose-1-phosphate aldolase. In the other eight patients, all of whom were demented, there

1 Non-specific degenerative changes included a variable degree of distension of neurones with cytoplasmic granularity, increased eosinophilia, and occasionally vacuolation with no specific histochemical staining reaction. Nuclear changes, including condensation of chromatin around the nucleolus with a ballooned appearance of the remainder of the nucleus, were often present.

The presence of P.A.S.-positive macrophages in the lamina propria has been reported as a non-specific abnormality, but this change, together with those already described, has been seen in cases of chronic constipation, megacolon, epilepsy, fibrocystic disease, chronic constipation, me were no clear indications, though one showed an exaggerated startle response to sound as described in Tay-Sachs's disease (Schneck et al., 1964).

All 11 patients with metachromatic leucodystrophy showed clear evidence of the disease on investigation by urine examination alone (three cases), nerve-conduction studies alone (three cases), or both (five cases). In one patient with normal conduction velocity the urine contained intracellular metachromatic material. Thus the two tests complemented each other in this series. In the metachromatic leucodystrophy patients biopsy was in fact often used as a confirmatory investigation, and it could be argued that its use was unjustified in some cases. With the diagnostic help now available from laboratory investigations in this condition and likely to increase with the wider use of urinary sulphatase estimations (Austin et al., 1964, 1966), biopsy, whether of rectum, brain, nerve, skin, or dental pulp (Gardner and Zeman, 1965), may well become obsolete. If biopsy is thought necessary when metachromatic leucodystrophy is strongly suspected, it would seem logical to biopsy a peripheral nerve as originally suggested by Thieffry and Lyon (1959), particularly if nerve-conduction velocity is slowed, rather than rectum or brain. In metachromatic leucodystrophy rectal biopsy is of value solely in showing changes in nerve fibres, and the same is true of appendix and dental pulp biopsy. Yudell et al. (1967) at the Mayo Clinic have now discontinued the use of rectal biopsy in metachromatic leucodystrophy in favour of biopsy of the sural nerve, which has so far given no false-negative results.

Diagnostic doubt in the neurolipidosis patients was least among those with Tay-Sachs disease because of the characteristic picture. For this group also, serum enzyme studies may well prove to be very reliable. With other forms of neurolipidosis clinical certainty is usually less, macular changes being less frequent and specific, and it is in this group that biopsy is likely to continue to be necessary, though improved chemical and electroencephalographic methods may in time provide tests of diagnostic reliability.

We cannot comment on the suggestion of Bodian and Lake that rectal biopsy might be of diagnostic value in sudanophilic leucodystrophy, since no cases have been investigated by it at this hospital. In this condition it would seem reasonable to prefer cerebral to rectal biopsy until such time as diagnostic changes have been found in the myenteric plexuses in cases at necropsy.

Rectal biopsy was negative in one patient with subacute sclerosing leucoencephalitis in whom brain biopsy was diagnostic. This boy was Case 8 in Bodian and Lake's series of cases with pathological changes other than neurolipidosis or metachromasia, two P.A.S.-positive cytoplasmic inclusions in rectal neurones being mentioned. This finding is quoted by Paine and Oppé (1966), but the inclusions seen in the rectal biopsy were not in fact typical of those seen in subacute sclerosing encephalitis, and similar inclusions have since been seen in a small number of rectal biopsies from patients not suffering from this condition.

\section{Summary}

A series of 165 rectal biopsies performed in conditions other than Hirschsprung's disease at the Hospital for Sick Children, Great Ormond Street, in the five years 1962-6, is reviewed. Thirty-three of these biopsies (20\%) showed diagnostic and 14 non-specific abnormalities, 118 being normal. Neurolipidosis and metachromatic leucodystrophy were diagnosed on 30 of the positive biopsies. The clinical features of the positive, "negative," and non-specific abnormal groups are reviewed. It is concluded that rectal biopsy is of particular value in the diagnosis of neurolipidosis and metachromatic leucodystrophy. However, it is suggested that where adequate laboratory facilities exist biopsy in the latter condition may become unnecessary 
and that increasing refinement of chemical and other investigations may in time render biopsy obsolete also in many cases of neurolipidosis.

Pneumoencephalography was of no value in selecting cases for rectal biopsy, since it showed cerebral atrophy with equal frequency in patients whose biopsies later did and did not show diagnostic changes.

No diagnostic abnormalities were found on rectal biopsy in patients without dementia, a positive family history of relevant disease or other features pointing strongly towards a specific neurological condition.

We thank the physicians and surgeons of the Hospital for Sick Children, Great Ormond Street, for permission to publish details of patients in their care.

REFERENCES

Allen, N. (1964). In Pediatric Neurology, edited by T. W. Farmer.
Austin, J., Armstrong, D., Shearer, L., and McAfee, D. (1966). Arch. Neurol. (Chic.), 14, 259.

McAfee, D., Armstrong, D., O'Rourke, M., Shearer, L., and Bachbawat, B. (1964). Biochem. F., 93, 15C.

Bodian, M., and Lake, B. D. (1963). Brit. F. Surg., 50, 702.

Fullerton, P. M. (1964). f. Neurol. Neurosurg. Psychiat., 27, 100.

Gardner, D. G., and Zeman, W. (1965). Develop. Med. Child Neurol., 7,620 .

Globus, J. H. (1942). 7. Mt Sinai Hosp., 9, 451.

Kobayashi, N. (1959). Amer. F. Path., 35, 591.

Lake, B. D. (1965). Arch. Dis. Childh., 40, 284.

Landing, B. H., and Freiman, D. G. (1957). Amer. F. Path., 33, 1.

Lyon, G., Arthuis, M., and Thieffry, S. (1961). Rev. Neurol., 104, 508.

Martin, L. W., Landing, B. H., and Nakai, H. (1963). F. Pediat., 62, 197.

Nakai, H., and Landing, B. H. (1960). Pediatrics. 26, 225.

Paine, R. S., and Oppé, T. E. (1966). Neurological Examination of Children. London.

Schneck, L., Maisel, J., and Volk, B. W. (1964). J. Pediat., 65, 749.

Thieffry, S., and Lyon, G. (1959). Rev. neurol., 100, 452.

Volk, B. W., Aronson, S. M., and Saifer, A. (1964). Amer. F. Med., 36, 481.

Yudell, A., Gomez, M. R., Lambert, E. H., and Dockerty, M. B. (1967). Neurology (Minneap.), 17, 103 .

\title{
Effect of Total Dose Infusion of Iron-dextran on Iron, Folate, and Vitamin $B_{12}$ Nutrition in Postpartum Anaemia
}

\author{
J. METZ,* M.D., M.C.PATH.; T. EDELSTEIN,* M.B., DIP.O.\&G. ; M. DIVARIS,* MED.TECH. ; S. S. ZAIL,* M.D.
}

Brit. med. F., 1967, 3, 403-406

The efficacy of total dose infusion of iron-dextran (T.D.I. Imferon) in the treatment of antepartum and postpartum irondeficiency anaemia is well established (Varde, 1964 ; Basu, 1965 ; Bonnar, 1965). Detailed studies on the effect of T.D.I. Imferon therapy on the iron, folate, and vitamin $B_{12}$ nutritional status of iron-deficient women have, however, not yet been reported. Such information is necessary in view of the poor response to T.D.I. Imferon noted in folate-deficient women (Basu, 1965 ; Bonnar, 1965), and the suggestion that reactions to T.D.I. Imferon may be related to folate deficiency (Clay et al., 1965; Lane and Scott, 1965). In the present study comprehensive tests of iron, folate, and vitamin $B_{12}$ nutrition were carried out before and after administration of T.D.I. Imferon therapy to postpartum anaemic subjects. This therapy generally resulted in restoration of normal nutrition, but the postpartum improvement in folate nutrition, shown in untreated control subjects, was retarded.

\section{Material and Methods}

All subjects were Bantu admitted to Baragwanath Hospital, Johannesburg (altitude 5,760 ft.; $1,756 \mathrm{~m}$.). Consecutive patients with haemoglobin levels of less than $10 \mathrm{~g} . / 100 \mathrm{ml}$. and decreased marrow iron stores on the third postpartum day were included in the study. A total of 81 patients received T.D.I. Imferon, and 61 of them returned for follow-up six weeks later; 12 of these 61 received folic acid as well as Imferon. Control subjects consisted of 18 patients who received no therapy. The control group is much smaller than the group receiving therapy, for during the course of the study pronounced differences between the groups became apparent, and it was not felt warranted to leave more patients untreated.

\section{Procedure}

Before therapy on the third postpartum day venous blood was drawn for measurement of haemoglobin, haematocrit, serum iron, unsaturated iron-binding capacity (U.I.B.C.), serum folate activity, serum vitamin- $\mathrm{B}_{12}$ concentration, and for the preparation of films. Blood for serum iron and U.I.B.C. estimation was allowed to drip direct from the needle into ironfree containers. Films were prepared from bone marrow aspirated from the sternum.

Imferon was administered as follows. The dose for each patient was calculated as described by the manufacturers. The Imferon was diluted in normal saline, not more than $20 \mathrm{ml}$. being added to a litre of saline. The infusion was started at 10-15 drops a minute until $100 \mathrm{ml}$. had been administered, and thereafter at 45 drops a minute. Before infusion basal readings of the pulse and blood pressure were made, and these were repeated at hourly intervals during the infusion. Any untoward symptoms occurring during the infusion were recorded. Fortyeight hours after completion of the infusion the site was examined for pain, tenderness, swelling, and redness, and the lower limbs were examined for evidence of venous thrombosis. The 14 patients who were to receive folic acid were then given folic acid tablets $(5 \mathrm{mg}$.) and instructed to take at least one tablet daily for a period of 40 days.

The patients were studied again six weeks later. All previous investigations, including bone-marrow-puncture, were repeated. Patients were re-examined for symptoms or signs of venous thrombosis at the site of infusion and in the legs. After withdrawal of the blood and marrow samples the investigation of the patients was complete; those who had received only Imferon therapy were supplied with folic acid tablets, and those who had received no therapy since delivery were treated with iron and folic acid by mouth.

\section{Laboratory Methods}

Haemoglobin was estimated as cyanmethaemoglobin, a commercially obtained standard being used. The haematocrit was

\footnotetext{
- Department of Haematology, South African Institute for Medical Research, and Department of Obstetrics, Baragwanath Hospital,
Johannesburg.
} 